Çukurova Üniversitesi Mühendislik Mimarlık Fakültesi Dergisi, 34(4), ss. 105-116, Aralık 2019

Çukurova University Journal of the Faculty of Engineering and Architecture, 34(4), pp. 105-116, December 2019

\title{
Micromeria Fruticosa L. Druce'un Süper Kritik Karbondioksit Kullanılarak Ekstraksiyonu ve Menton, İsomenton ve Pulegon Miktarı Üzerine Ekstraksiyon Koşullarının Optimizasyonu
}

\author{
Murat TÜRK ${ }^{* 1}$ \\ ${ }^{1}$ Çukurova Üniversitesi, Ceyhan Meslek Yüksekokulu, Ceyhan, Adana
}

Geliş tarihi: 10.10.2019

Kabul tarihi: 20.12 .2019

$\ddot{O} \mathbf{z}$

Taşnanesi olarak da adlandırılan Micromeria fruticosa L. Druce, tıbbi özelliklere sahip bir Akdeniz bitkisidir. Bu çalışmada, Micromeria fruticosa L. Druce' un süper kritik $\mathrm{CO}_{2}$ ekstraksiyonunda menton, isomenton ve pulegon derişimlerine etki eden parametre değerlerini optimize etmek için yanıt yüzey yöntemi (RSM) kullanılmıştır. Bu amaçla 3-faktör ve 3-düzey Box-Behnken dizaynı uygulanarak ve sıcaklık, basınç ve zaman parametreleri bağımsız değişkenler olarak seçilmiştir. Elde edilen sonuçların değerlendirilmesi Design-Expert yazılımı kullanılarak gerçekleştirilmiştir. Yanıt ve bağımsız değişkenler arasındaki matematiksel ilişki quadratik denklem ile açıklanmıştır. Süper kritik $\mathrm{CO}_{2}$ ekstraksiyonu için deneysel sonuçlar ile tahminlenen sonuçlar arasında istatistiksel olarak anlamlı bir ilişki elde edilmiştir. Maksimum menton, isomenton ve pulegon derişimlerine ulaşmak için optimum deney koşulları $47,16^{\circ} \mathrm{C}$, $216,99 \mathrm{~atm}$ ve $22,45 \mathrm{dk}$ olarak bulunmuştur. Micromeria fruticosa L. Druce'un temel bileşenleri açısından, süper kritik $\mathrm{CO}_{2}$ kullanılarak ekstraksiyon koşullarının optimizasyonu ile ilgili bir çalışmaya literatürde rastlanmamıştır. Bu çalışmanın ilk kez çalışılmış olması hem literatüre katkısı açısından hem de elde edilen sonuçların farmakoloji, gıda ve nutrosotik endüstrisine katkı sağlaması açısından önemli olacağı düşünülmektedir.

Anahtar Kelimeler: Süper kritik karbondioksit, Micromeria fruticosa L., Yanıt yüzey yöntemi

\section{Extraction of Micromeria Fruticosa L. Druce by Using Super Critical Carbon Dioxide and Optimization of Extraction Conditions on Amount of Menthone, Isomenthone and Pulegone}

\begin{abstract}
Micromeria fruticosa L. Druce, also called "taşnanesi", is a Mediterranean plant with medicinal properties. In this study, response surface methodology (RSM) was used to optimize parameter values that have an effect on the concentration of menthone, isomenthone and pulegone in the supercritical $\mathrm{CO}_{2}$ extraction of Micromeria fruticosa L. Druce. For this purpose, 3-factor and 3-level Box-Behnken design was applied and temperature, pressure and time were chosen as independent variables. The assessment of results obtained were carried out by using Design-Expert software. The mathematical relationship between the responses and independent parameters were explained by quadratic equation. For
\end{abstract}

*Sorumlu yazar (Corresponding author): Murat TÜRK, murturk@cu.edu.tr 
Micromeria Fruticosa L. Druce'un Süper Kritik Karbondioksit Kullanilarak Ekstraksiyonu ve Menton, İsomenton ve Pulegon Miktarı Üzerine Ekstraksiyon Koşullarının Optimizasyonu

supercritical $\mathrm{CO}_{2}$ extraction, the statistically significant relationship was obtained between the experimental results and predicted results. To reach the maximum concentration of menthone, isomenthone and pulegone, the optimum experimental conditions were found to be $47.16{ }^{\circ} \mathrm{C}, 216.99 \mathrm{~atm}$ ve $22.45 \mathrm{~min}$. In terms of the major components of Micromeria fruticosa L. Druce, a study on the optimization of extraction conditions using supercritical $\mathrm{CO}_{2}$ has not been found in the literature. The fact that this study has been studied for the first time is considered to be important both in terms of its contribution to the literature and in terms of contributing to the pharmacology, food and nutraceuticals industries.

Keywords: Supercritical carbon dioxide, Micromeria fruticosa L, Response surface methodology

\section{GİRIŞ}

Lamiaceae ailesine ait aromatik bitkiler, 220 cins ve 4000 tür tarafindan temsil edilmektedir. Hoş kokulu ve tıbbi özelliklere sahip olduklarından her zaman büyük ilgi görmüşlerdir. Diğer birçok Lamiaceae türleri gibi Micromeria cinsinin üyeleri tipik Akdeniz bitkileridir. Bu cins Türkiye'de 12'si endemik olan 14 tür ve 22 taksonla temsil etmektedir. Taşnanesi olarak da adlandırılan, Micromeria fruticosa, Türkiye'nin güney ve doğu Anadolu bölgesinin kayalık bölgelerinde, 20-60 cm yüksekliğe kadar büyüyen ve ezildiğinde nane kokan, çok yıllık bir bitkidir. Micromeria türleri, genellikle bitki çayı olarak ve geleneksel tıpta nane yerine kullanılmıştır. Micromeria türlerinin kalp hastalıklarında, baş ağrısında, yaralarda ve deri enfeksiyonlarında kullanıldığı, ayrıca bu türlerin anti mikrobiyal, anti bakteriyel, anti fungal ve antioksidan gibi biyolojk aktivitelere sahip olduğu, yatıştırıcı, anestetik, antiseptik, düşük ilacı, antiromatik, CNS-Uyarıcı ve soğuk algınlığ1 tedavisinde kullanıldığı bildirilmiştir [1-8]. Micromeria fruticosa türlerinin kimyasal kompozisyonu birçok çalışmada kapsamlı bir şekilde incelenmiştir. Micromeria fruticosa'ın ana bileşeni tüm çalışmalarda pulegon olarak belirlenmiştir. Micromeria fruticosa türlerinde menton, piperitenon, isomenton, mentol ve linalol gibi ikincil ana bileşenlerde gözlenmiştir. Micromeria fruticosa L.'un bu çalışmadaki temel bileşenlerinin yapıları Şekil 1'de gösterilmiştir. Micromeria fruticosa L. Druce'un temel bileşenlerinden Pulegon'un antifungal, antimikrobiyal ve antioksidan aktivite gösterdiği bildirilmiştir. Ayrıca menton ve pulegon'un indirgenmesi ile ekonomik değeri çok yüksek olan mentol elde edilebilmektedir (dünya genelinde yılda 4500 ton üretimi). Bu bileşenleri elde etmek için kullanılan ekstraksiyon yöntemleri hidro destilasyon ve maserasyon yöntemidir [9-12].

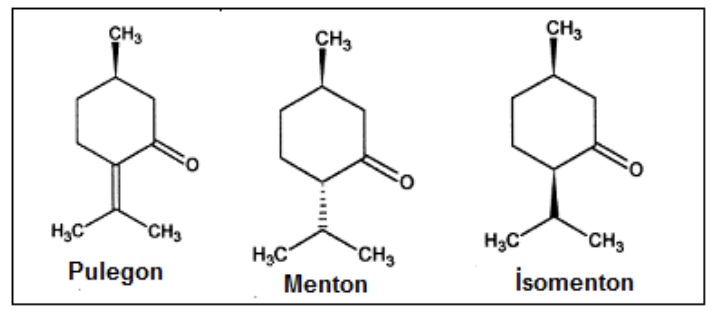

Şekil 1. Micromeria fruticosa L. Druce'dan elde edilen temel bileşenlerinin yapıları

Dünyada, bitkisel tıbbi ilaçlara, doğal gıda takviyelerine gösterilen ilginin artmasıyla, tıbbi bitki ekstraktı üreticileri ve uçucu yağ üreticileri, belirli bir kalitede, tekrarlanabilir ekstraksiyon yöntemleri kullanmaya başlamışlardır. $\mathrm{Bu}$ amaçla kullanılan yaygin yöntemler; hidro destilasyon (su, buhar ve subuhar destilasyonları), maserasyon (1slatma), demleme, sızdırma, parçalama, Soxhlet ekstraksiyonu, organik çözücülerle ekstraksiyon, mikro dalga yardımıyla ekstraksiyon, süper kritik akışkan ekstraksiyonu, ultrasonik ekstraksiyon ve hidroflorokarbon çözücülerle ekstraksiyondur. Aromatik bitkiler için hidro destilasyon (su, buhar ve su-buhar destilasyonları), ve maserasyon (1slatma) en yaygın uygulanan yöntemlerdir. Bu yöntemlerden, doğal bileşiklerden doğal biyoaktif moleküllerin ekstraksiyonu için süper kritik akışkan ekstraksiyonu, 20. yy'ın ikinci yarısında alternatif bir yöntem olmuştur. Bunun en önemli sebepleri ise, çalışma sıcaklığının ve ekstraksiyon sürelerinin düşük olması ve dolayısıyla isıl olarak bozulabilecek doğal 
bileşenlerin zarar görmesinin engellenmiş olmasıdır. Özellikle 1980'lerden itibaren yapılan yoğun araştırmalar ile günümüzde süper kritik akışkanlarla ekstraksiyona ait tüm teknik ve ekonomik sorunlar yanıtlanmıştır [13]. Süper kritik akışkan, aynı zamanda "yoğun gaz" olarak da tanımlanabilir. Sıcaklığı kritik sıcaklığın üzerinde ve basıncı da kritik basıncın üzerinde olan akışkanlardır. Bir akışkanın süper kritik akışkan olarak adlandırılması için indirgenmiş sıcaklığın Tr 1,2-1,3 arasında olması $(\mathrm{Tr}=\mathrm{T} / \mathrm{Tc})$ gerekir. İndirgenmiş basınç $\mathrm{Pr}$ ise kullanılan sistemin teknik olarak elverdiği ölçüde olması yeterlidir $(\mathrm{Pr}=\mathrm{P} / \mathrm{PC})$. Uygun koşullar sağlandığında herhangi bir Sivı süper kritik koşullarına ulaşabilir. Ancak sadece kritik sıcaklığ oda sıcaklığının çok üzerinde olmayan sıvılar, tıbbi aromatik bitkilerin ekstraksiyonunda alternatif bir çözücü olabilirler. Karbon dioksit, düşük kritik sıcaklığı ve basıncı nedeniyle en çok uygulanan çözücü olmuştur $\left(\mathrm{T}_{\mathrm{C}}=31,06{ }^{\circ} \mathrm{C}\right.$ ve $\mathrm{P}_{\mathrm{C}}=73,81$ bar $)$. Süper kritik karbondioksit aynı zamanda toksik ve alev alıcı olmayışı, ucuz ve kolay temin edilebilir olması nedeniyle de alternatif bir çözücüdür. Ayrıca, süper kritik akışkanın yoğunluğu da önemli bir parametredir. Süper kritik akışkanların ekstraksiyon çözücüsü olabilmesi yoğunluğu ile doğrudan ilişkilidir. Chrastil, yoğunluk ve çözünürlük arasındaki ilişkiyi Eşitlik 1'de verildiği gibi ifade etmiştir [14].

$\mathrm{s}=\rho^{\mathrm{a}} \exp (\mathrm{b} / \mathrm{T}+\mathrm{c})$

s çözünürlük; $\rho$ çözücünün yoğunluğu; T mutlak çalışma sıcaklığı; a, b ve c düzeltme sabitleridir.

Bir akışkan kritik şartlara yaklaştıkça yoğunluğu bir sıvının yoğunluğuna yaklaşır. Şekil 2'de $\mathrm{CO}_{2}$ için yoğunluk izotermleri indirgenmiş basınca karş1 grafiğe geçirilmiştir. Buradan $\mathrm{T}=35^{\circ} \mathrm{C}$ ve $\mathrm{P}=200$ bar da $\rho=866 \mathrm{~kg} / \mathrm{m}^{3}$ olduğu görülebilir. Çözücü yoğunluğu başarılı bir süper kritik akışkan ekstraksiyonunda anahtar faktördür.

Süper kritik akışkanların ekstraksiyon çözücüsü olarak kullanımı, kendilerine özgü solvasyon özellikleri ve düşük viskoziteleri nedeniyle tercih edilmektedir. Yüksek difüzyon hızı, hızlı kütle transferi dolayısıyla hızlı ekstraksiyon sunar [15]. Süper kritik akışkan ekstraksiyonunun bitkisel matris içinde uçucu yağlar üzerinde etkili olan, kütle transfer mekanizmaları çoğunlukla difüzyon işlemleriyle ilişkilidir [16].

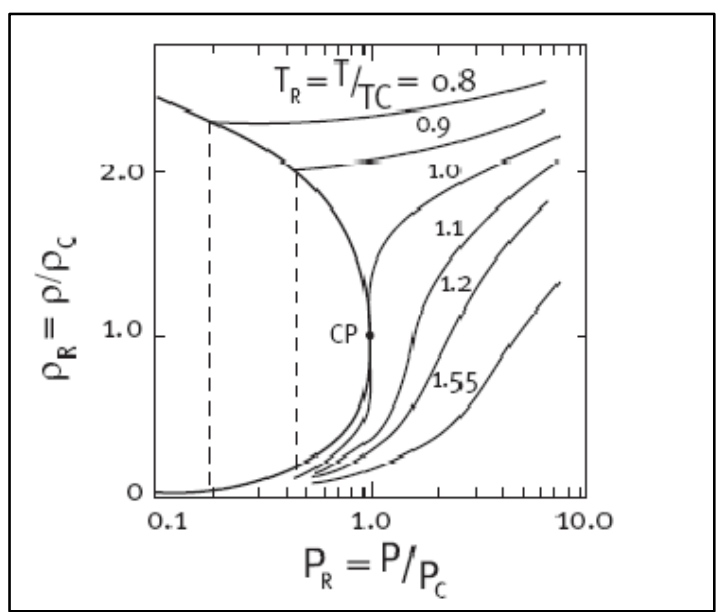

Şekil 2. $\mathrm{CO}_{2}$ için yoğunluk/basınç diyagramı

Günümüzde bitki ekstraksiyonlarında çalışılan koşulların matematiksel ve istatistiksel olarak optimizasyonu da incelenmektedir. $\mathrm{Bu}$ amaçla en sık kullanılan yöntem Yanıt Yüzey Yöntemidir (Response Surface Methodology, RSM). Yanıt yüzey yöntemi (RSM) sahip olduğu avantajlardan dolayı günümüzde uygulamalı bilim ve mühendislik dallarında kullanılan matematiksel ve istatistiksel bir yöntemdir [17]. $\mathrm{Bu}$ yöntem teknolojik proseslerin matematiksel modellemelerinde ve optimizasyonunda sıç̧a kullanılmaktadır. Box ve Wilson en az sayıda gözlem değeri ile yanıt yüzeyi üzerinde yanıt değişkeninin maksimum değerini aldığı noktaya erişilmesi amaçlanan deneme düzenlerini ortaya koymuşlardır. Bu yöntem birçok deney türü için ortaya çıkan problemleri eş zamanlı olarak çözmek ve cevapları da eş zamanlı olarak optimize etmekte faydalanılan kullanışlı ve etkili bir metottur [18]. Yanıt yüzey yöntemi model regresyon analizi yardımıyla oluşturulur. Bir faktörün temel etkisinin veya diğer faktörlerle etkileşiminin yanıt değişkeninin değerinde ne derece önemli etkiye sahip olduğuna regresyon katsayıları yardımıyla karar verilir. Yanıt yüzey yöntemi kullanılarak birden fazla değişkenin örneğin $\mathrm{pH}$, 
Micromeria Fruticosa L. Druce'un Süper Kritik Karbondioksit Kullanilarak Ekstraksiyonu ve Menton, İsomenton ve Pulegon Miktarı Üzerine Ekstraksiyon Koşullarının Optimizasyonu

konsantrasyon, zaman, sicaklık gibi yanıt üzerindeki etkileri araştırılıp optimum değerleri tespit edilebilir. Sonuçlar üç boyutlu grafik ve kontur haritası olarak verilebilir. Az sayıda deneysel kombinasyon kullanilarak test edilmeyen faktör değeri ve bunların kombinasyonları hakkında tahmin yapılabilir [19]. Yanıt yüzey oluşturmadaki amaç deneysel bir çalışmada sonuç üzerinde etkili olan çok sayıdaki parametreden oluşan bir tasarım düzleminde belirli özellikleri sağlayan bir bölgeyi ve bu bölgeye ait optimum noktayı tahmin etmektir. Elde edilen fonksiyon deneysel verileri temsil etmekle birlikte, model uyumunun fazla olması büyük önem taşımaktadır. $\mathrm{Bu}$ amaçlı çalışmalarda;

$\mathrm{Y}=\mathrm{f}\left(\mathrm{X}_{1}, \mathrm{X}_{2}, \ldots \ldots \ldots, \mathrm{X}_{\mathrm{n}}\right)+\varepsilon$

Eşitlik 2 esas alınır. Burada Y bağımlı yanıt değișkeni, f bağımsız değişkenler olarak bilinen kantitatif değişkenler olan $\mathrm{X}_{1}, \mathrm{X}_{2}, \ldots, \mathrm{X}_{\mathrm{n}}{ }^{\prime}$ in fonksiyonu ve $\varepsilon$ ise tesadüfi hata terimidir.

Deneysel tasarım yani istatistiksel tasarım en az sayıda deneyle maksimum bilgiyi elde etmek için deneylerin nasıl planlanacağı ve yapılacağının metodudur. Tasarım uygulanmadan önce literatürler taranarak ve ön deneyler yapılarak yanıtı etkileyen bağımsız değişkenlerin minimum ve maksimum değerleri belirlenmelidir [20]. Deneysel tasarım seçimi yapılmadan önce ise aşağıdaki aşamalar tespit edilmelidir [21].

- Problemin durumu ve tanımlanmasi,

- Faktörler, seviye ve aralıklarının seçilmesi,

- Cevap değişkeninin seçilmesi,

- Deneysel tasarım matrisi oluşturulmasi,

- Deneylerin gerçekleştirilmesi,

- Verilerin istatistiksel analizinin yapılması,

- Sonuçların değerlendirilmesi

Deneysel tasarım birkaç faktörün eş zamanlı değiştirilebilmesi ve her bir faktörün bağımsızca değerlendirilmesini mümkün hale getirdiğinden geleneksel deney yöntemlerini göre daha az deney yapılarak daha kısa sürede daha doğru sonuç alınmasını sağlar [22].
$\mathrm{Bu}$ çalışmanın amacı, Kadirli-Osmaniye bölgesinden toplanan Micromeria fruticosa $\mathrm{L}$. Druce yapraklarından süper kritik karbondioksit ekstraksiyonu ile maksimum düzeyde pulegon, menton ve isomenton elde etmek için ekstraksiyon verimine etki eden parametre değerlerinin optimizasyonunu RSM metodunu uygulayarak belirlemektir.

Literatürde, Micromeria fruticosa L. Druce ile ilgili böyle bir çalışmaya rastlanmamış olması, literatüre katkı sağlayacağı gibi aynı zamanda elde edilen bulguların gida, farmakoloji ve gida takviye sektörüne de faydalı olabileceği düşünülmektedir.

\section{MATERYAL VE METOT}

\subsection{Materyal}

\subsubsection{Bitki Kaynağı}

Micromeria fruticosa L. Druce 2011 y1lı haziran ayında, Kadirli-Osmaniye bölgesinden toplanmıştır. Bitkinin tanımlanması, Ç.Ü. FenEdebiyat Fakültesi Biyoloji Bölümü öğretim üyelerinden Prof. Dr. Necattin TÜRKMEN tarafından yapılmıştır.

Micromeria fruticosa L. Druce yaprakları, saf su ile yıkandıktan sonra oda koşullarında karanlıkta 2 hafta boyunca kurutulmuştur. Kurutulmuş örnekler, 5 mm'lik iç çapa sahip huni boynundan geçecek şekilde elle öğütülmüştür (Şekil 4'de kullanılan kolonun iç çapı 7 mm'dir). Kurutulmuş ve öğütülmüş bitki örnekleri, analizden önce plastik şişelerde buzdolabında $4 \quad{ }^{\circ} \mathrm{C}$ 'de saklanmıştır.

\subsubsection{Kimyasallar}

Hekzan (Merck Analitik saflıkta), diklorometan (Mecrck Analitik saflıkta), $\mathrm{CO}_{2(\mathrm{~s})}$ (Linde \%99,9999), p-menton (Sigma-Aldrich analitik standart \%98,5), isomenton (SigmaAldrich analitik standart \%90,0) ve pulegon (Sigma-Aldrich analitik standart \%98,5). 


\subsection{Metot}

\subsubsection{Süper Kritik $\mathrm{CO}_{2}$ Yöntemiyle Bitki Ekstraktlarının Hazırlanması}

Ekstraksiyon işlemi Çukurova Üniversitesi FenEdebiyat Fakültesi Kimya Bölümü Organik Kimya Araştırma Laboratuvarında oluşturulan sistemin kullanılmasıyla gerçekleştirilmiştir (Şekil 3).

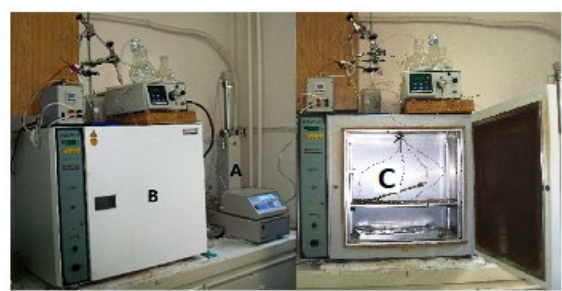

Şekil 3. Süper kritik akışkan ekstraksiyon sistemi A: ISCO pompa; B: Firın C: Ekstrasiyon hücresi

Çalışmada kullanılan parametreler ve aralıkları ön denemeler yapılarak belirlenmiştir. Ekstraksiyon hücresi 2,0 g örnekle doldurulduktan sonra istenilen ekstraksiyon sıcaklığında çalışmak için fırın içine yerleştirilmiştir. Bir ISCO pompası yardımıyla istenilen basınçta süper kritik $\mathrm{CO}_{2}$ hücreye gönderilerek, Çizelge 2'de verilen deneysel koşullarla $30 \mathrm{dk}$ statik ve $20 \mathrm{dk}$ dinamik ekstraksiyon işlemi gerçekleştirilmiştir. Ekstrakte edilen bileşenleri toplamak için, yaklaşık $2 \mathrm{~mL} \mathrm{dk}^{-1}$ akış hızında bir restriktör (Suprex marka) kullanılmıştır.

\subsubsection{Kromatografik Ayırma ve Tanımlama}

Tüm deneylerden elde edilen ekstraktlar, 2 mL'lik viyale alınmış, 50 split oranı kullanılarak, $1 \mu \mathrm{L}$ örnek analiz için kolona enjekte edilmiştir. Analizlerde helyum taşıyıcı gaz olarak kullanılmış ve akış hızı $1.0 \mathrm{~mL} \mathrm{dk}^{-1}$ olarak ayarlanmıştır. Kolon sicaklığı, $50{ }^{\circ} \mathrm{C}$ 'den $240{ }^{\circ} \mathrm{C}^{\prime}$ ye dakikada $3{ }^{\circ} \mathrm{C}$ 'lik artışlarla yükseltilmiştir. Enjeksiyon portunun sıcaklığ $250{ }^{\circ} \mathrm{C}$ olarak ayarlandı. GC-MS analizleri bir otosampler yardımıla Termo-Finnigan Trace marka kütle spektrometresinde elektron impakt $(70 \mathrm{eV})$ ile yapılmıştır. Kromatografik ayırma TR-MS-5 (60 m x 0,25 mm x 0,25 $\mu \mathrm{m}, \% 5$ fenil polisiloksan) kolonda gerçekleştirilmiştir. Her bir bileşen, kütle spektrumlarının Wiley07 ve NIST(2005) kütüphanesinden yararlanılarak karşılaştırma ile tanımlanmıştır. Menton, isomenton ve pulegonun kantitatif analizi iç standart yöntemiyle yapılmıştır (Şekil 4).

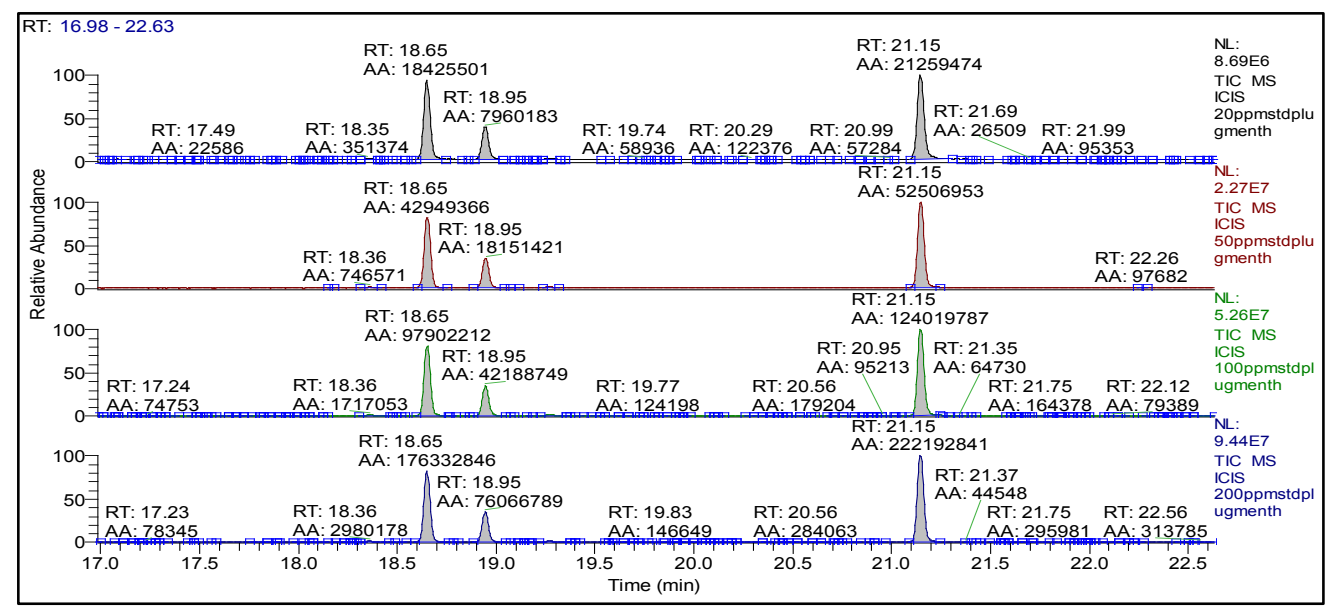

Şekil 4. Menton, isomenton ve pulegon standartlarının 20-50-100-200 ppm derişimlerinde kromatogramları

Menton, isomenton ve pulegon standartlarının 21,15'dir (Şekil 5). alıkonma zamanları sirasiyla, 18,65, 18,95, 
Micromeria Fruticosa L. Druce'un Süper Kritik Karbondioksit Kullanilarak Ekstraksiyonu ve Menton, İsomenton ve Pulegon Miktarı Üzerine Ekstraksiyon Koşullarının Optimizasyonu

\subsubsection{Süper Kritik $\mathrm{CO}_{2}$ Ortamında Micromeria fruticosa L. Druce'un Ekstraksiyonu İçin Box-Behnken Dizaynı Uygulanması}

$\mathrm{Bu}$ çalışmada, Micromeria fruticosa $\mathrm{L}$. Druce'un süper kritik $\mathrm{CO}_{2}$ ekstraksiyonu ile menton, isomenton ve pulegon temel bileşenleri için yanıt yüzey yöntemi kullanılarak optimizasyonu incelenmiștir. Bağımsız değişkenler sıcaklık, basınç ve ekstraksiyon süresi olarak seçilmiş ve 3-faktör 3-Düzey Box-Behnken dizaynı uygulanmış ve elde edilen sonuçların değerlendirilmesi Design-Expert yazılımı kullanılarak gerçekleştirilmiştir. Bağımsız değişkenler ve düzeyleri Çizelge 1'de verilmiş̧ir.

Cizelge 1. Deney parametreleri ve değerleri

\begin{tabular}{|l|c|c|c|c|}
\hline Bağımsı̆ & \multirow{2}{*}{ Kod } & \multicolumn{3}{|c|}{ Düzey } \\
\cline { 3 - 5 } & & -1 & 0 & 1 \\
\hline Siçisken & & 35 & 45 & 55 \\
\hline Basınç (atm) & $\mathrm{X}_{2}$ & 80 & 190 & 300 \\
\hline Süre (dk) & $\mathrm{X}_{3}$ & 5 & 25 & 45 \\
\hline
\end{tabular}

Çizelge 1'de Regresyon ve varyans analizleri (ANOVA) Design Expert Yazılımı (Version 10.0.6.0) ile yapılmıştır. $X_{1}, X_{2}$, ve $X_{3}$ sırasıyla sıcaklık, basınç ve ekstraksiyon süresini göstermektedir.

\section{BULGULAR VE TARTIŞMA}

\subsection{Micromeria fruticosa $L$. Druce'un Süper Kritik $\mathrm{CO}_{2}$ Ekstraksiyonunun Yanıt Yüzey Yöntemi ile İncelenmesi}

Box-Behnken dizaynı ile oluşturulan deneysel setin yanitları (menton, isomenton ve pulegon derişimleri) Çizelge 2'de verilmiştir.

Çizelge 2'den görüleceği üzere en yüksek ve en düşük bileşen derişimleri $(\mathrm{mg} / \mathrm{g}$ bitki) sırasıyla 4,58-0,10 (mg menton/g bitki); 10,87-0,24 (mg isomenton/g bitki) ve 27,07-0,90 (mg pulegon/g bitki) olarak belirlenmiştir. ANOVA analizleri sonucunda, menton isomenton ve pulegon için önerilen ikinci dereceden eşitliğin regresyon katsayıları aşağıda Eşitlik 1, 2 ve 3'de verildiği şekilde belirlenmiştir.

Çizelge 2. Deneysel ve tahminlenen menton, isomenton ve pulegon derişimleri

\begin{tabular}{|c|c|c|c|c|c|c|c|c|}
\hline $\begin{array}{c}\text { Sicaklık } \\
\left({ }^{\circ} \mathrm{C}\right)\end{array}$ & $\begin{array}{c}\text { Basınç } \\
(\mathrm{atm})\end{array}$ & $\begin{array}{c}\text { zaman } \\
\text { (dakika) }\end{array}$ & $\begin{array}{c}\text { Menton } \\
\text { deneysel } \\
\mathrm{mg} / \mathrm{g} \text { bitki }\end{array}$ & $\begin{array}{c}\text { Menton } \\
\text { tahmini } \\
\mathrm{mg} / \mathrm{g} \text { bitki }\end{array}$ & $\begin{array}{c}\text { Isomenton } \\
\text { deneysel } \\
\mathrm{mg} / \mathrm{g} \text { bitki }\end{array}$ & $\begin{array}{c}\text { Isomenton } \\
\text { tahmini } \\
\mathrm{mg} / \mathrm{g} \text { bitki }\end{array}$ & $\begin{array}{c}\text { Pulegon } \\
\text { deneysel } \\
\mathrm{mg} / \mathrm{g} \text { bitki }\end{array}$ & $\begin{array}{c}\text { Pulegon } \\
\text { tahmini } \\
\mathrm{mg} / \mathrm{g} \text { bitki }\end{array}$ \\
\hline 35 & 80 & 25 & 1,14 & 1,64 & 2,03 & 2,85 & 4,02 & 5,40 \\
\hline 35 & 190 & 5 & 3,09 & 2,77 & 5,45 & 5,24 & 13,51 & 14,68 \\
\hline 35 & 190 & 45 & 0,10 & 0,51 & 2,89 & 3,16 & 19,69 & 15,06 \\
\hline 35 & 300 & 25 & 2,57 & 1,94 & 6,30 & 5,45 & 13,96 & 16,00 \\
\hline 45 & 80 & 45 & 0,01 & $-0,93$ & 0,24 & $-0,83$ & 0,90 & 4,12 \\
\hline 45 & 190 & 25 & 4,18 & 4,38 & 9,70 & 9,60 & 23,26 & 24,91 \\
\hline 45 & 190 & 25 & 4,39 & 4,38 & 8,24 & 9,60 & 24,40 & 24,91 \\
\hline 45 & 190 & 25 & 4,58 & 4,38 & 10,87 & 9,60 & 27,07 & 24,91 \\
\hline 45 & 300 & 5 & 0,10 & 1,03 & 3,09 & 4,17 & 25,42 & 22,20 \\
\hline 45 & 300 & 45 & 0,22 & 0,39 & 1,28 & 1,87 & 7,29 & 9,84 \\
\hline 55 & 80 & 25 & 0,97 & 1,58 & 1,99 & 2,83 & 3,56 & 1,52 \\
\hline 55 & 190 & 5 & 2,54 & 2,11 & 5,80 & 5,54 & 14,07 & 18,66 \\
\hline 55 & 190 & 45 & 2,23 & 2,53 & 3,84 & 4,06 & 11,93 & 10,76 \\
\hline 55 & 300 & 25 & 3,87 & 3,36 & 7,48 & 6,67 & 20,95 & 19,56 \\
\hline 45 & 80 & 5 & 0,47 & 0,27 & 1,03 & 0,43 & 1,83 & $-0,72$ \\
\hline
\end{tabular}

Ymenton $=+4,38+0,34 \mathrm{X}_{1}+0,52 \mathrm{X}_{2}-0,46 \mathrm{X}_{3}+$ $0,37 \mathrm{X}_{1} \mathrm{X}_{2}+0,67 \mathrm{X}_{1} \mathrm{X}_{3}+0,14 \mathrm{X}_{2} \mathrm{X}_{3}-0,23 \mathrm{X}_{1}^{2}-$ $2,02 \mathrm{X}_{2}^{2}-2,17 \mathrm{X}_{3}^{2}($ Eşitlik 1)
Yisomenton $=+9,60+0,30 \mathrm{X}_{1}+1,61 \mathrm{X}_{2}-0,89 \mathrm{X}_{3}+$ $0,31 \mathrm{X}_{1} \mathrm{X}_{2}+0,15 \mathrm{X}_{1} \mathrm{X}_{3}-0,26 \mathrm{X}_{2} \mathrm{X}_{3}-1,03 \mathrm{X}_{1}^{2}-$ $4,12 \mathrm{X}_{2}^{2}-4,07 \mathrm{X}_{3}^{2}($ Eşitlik 2) 
Ypulegon $=+24,91-0,079 \mathrm{X}_{1}+7,16 \mathrm{X}_{2}-1,88 \mathrm{X}_{3}$ $+1,86 \mathrm{X}_{1} \mathrm{X}_{2}-2,07 \mathrm{X}_{1} \mathrm{X}_{3}-4,30 \mathrm{X}_{2} \mathrm{X}_{3}-4,18 \mathrm{X}_{1}^{2}-$ $10,11 X_{2}^{2}-5,94 X_{3}^{2}$ (Eşitlik 3)
Eşitlikte $\mathrm{Y}$; menton, isomenton ve pulegon derişimini ( $\mathrm{mg} / \mathrm{g}$ bitki), $\mathrm{X}_{1}, \mathrm{X}_{2}$, ve $\mathrm{X}_{3}$ sırasıyla sıcaklık, basınç ve ekstraksiyon süresini göstermektedir.

Çizelge 3. Menton için önerilen kuadratik modelin Anova sonuçları

\begin{tabular}{|c|c|c|c|c|c|}
\hline Source & $\begin{array}{c}\text { Sum of } \\
\text { Squares }\end{array}$ & df & $\begin{array}{c}\text { Mean } \\
\text { Square }\end{array}$ & F Değeri & $\begin{array}{c}\text { p-değeri } \\
\text { Prob }>\text { F }\end{array}$ \\
\hline Model & 37,23 & 9 & 4,14 & 5,56 & 0,0367 \\
\hline $\mathrm{X}_{1}$ & 0,92 & 1 & 0,92 & 1,23 & 0,3172 \\
\hline $\mathrm{X}_{2}$ & 2,17 & 1 & 2,17 & 2,92 & 0,1481 \\
\hline $\mathrm{X}_{3}$ & 1,66 & 1 & 1,66 & 2,23 & 0,1959 \\
\hline $\mathrm{X}_{1} \mathrm{X}_{2}$ & 0,54 & 1 & 0,54 & 0,73 & 0,4331 \\
\hline $\mathrm{X}_{1} \mathrm{X}_{2}$ & 1,80 & 1 & 1,80 & 2,41 & 0,1810 \\
\hline $\mathrm{X}_{2} \mathrm{X}_{3}$ & 0,084 & 1 & 0,084 & 0,11 & 0,7504 \\
\hline $\mathrm{X}_{1}{ }^{2}$ & 0,19 & 1 & 0,19 & 0,26 & 0,6333 \\
\hline $\mathrm{X}_{2}{ }^{2}$ & 15,04 & 1 & 15,04 & 20,21 & 0,0064 \\
\hline $\mathrm{X}_{3}{ }^{2}$ & 17,31 & 1 & 17,31 & 23,27 & 0,0048 \\
\hline Residual & 3,72 & 5 & 0,74 & & \\
\hline Lack of Fit $\mathrm{R}^{2} 0.91$ & 3,64 & 3 & 1,21 & 30,31 & 0,0321 \\
\hline
\end{tabular}

Önerilen kuadratik eşitliklerin ANOVA sonuçları çizelge 3 , çizelge 4 ve çizelge 5 de verilmiştir. pdeğeri 0,05 'ten küçük olan model terimlerindeki değişimler anlamlı değişimler olarak kabul edilmiştir. Bu durumda menton için $\mathrm{X}_{2}{ }^{2}$ ve $\mathrm{X}_{3}{ }^{2}$ deki değişimler, isomenton için $\mathrm{X}_{2}, \mathrm{X}_{2}{ }^{2}$ ve $\mathrm{X}_{3}{ }^{2}$ deki değişimler ve pulegon için $X_{2}, X_{2}{ }^{2}$ ve $X_{3}{ }^{2}$ değişimler anlamlıdır. Menton için önerilen model için belirleme katsayısı $\left(\mathrm{R}^{2}\right) 0,91$, isomenton için $\mathrm{R}^{2}, \quad 0,94$ ve pulegon için $\mathrm{R}^{2}, 0,91$ olarak bulunmuştur. $\mathrm{Bu}$ sonuçlarla elde edilen eşitliklerde menton ve pulegon için önerilen kuadratik modeldeki değişimleri \%91 oranında, isomenton için ise \%94 başarı ile tahminlemektedir.

Çizelge 4. İsomenton için önerilen kuadratik modelin Anova sonuçları

\begin{tabular}{|c|c|c|c|c|c|}
\hline Source & $\begin{array}{c}\text { Sum of } \\
\text { Squares }\end{array}$ & df & $\begin{array}{c}\text { Mean } \\
\text { Square }\end{array}$ & f Değeri & $\begin{array}{c}\text { p-değeri } \\
\text { Prob }>\text { F }\end{array}$ \\
\hline Model & 144,31 & 9 & 16,03 & 8,46 & 0,0150 \\
\hline $\mathrm{X}_{1}$ & 0,74 & 1 & 0,74 & 0,39 & 0,5585 \\
\hline $\mathrm{X}_{2}$ & 20,67 & 1 & 20,67 & 70,90 & 0,0214 \\
\hline $\mathrm{X}_{3}$ & 6,34 & 1 & 6,34 & 3,34 & 0,1271 \\
\hline $\mathrm{X}_{1} \mathrm{X}_{2}$ & 0,37 & 1 & 0,37 & 0,20 & 0,6763 \\
\hline $\mathrm{X}_{1} \mathrm{X}_{3}$ & 0,090 & 1 & 0,090 & 0,047 & 0,8361 \\
\hline $\mathrm{X}_{2} \mathrm{X}_{3}$ & 0,26 & 1 & 0,26 & 0,14 & 0,7263 \\
\hline $\mathrm{X}_{1}{ }^{2}$ & 3,95 & 1 & 3,95 & 2,08 & 0,2086 \\
\hline $\mathrm{X}_{2}{ }^{2}$ & 62,65 & 1 & 62,65 & 33,04 & 0,0022 \\
\hline $\mathrm{X}_{3}^{2}$ & 61,29 & 1 & 61,29 & 32,32 & 0,0023 \\
\hline Residual & 9,48 & 5 & 1,90 & & \\
\hline Lack of Fit $\mathrm{R}^{2} 0.94$ & 6,01 & 3 & 2,00 & 1,15 & 0,4955 \\
\hline
\end{tabular}


Micromeria Fruticosa L. Druce'un Süper Kritik Karbondioksit Kullanilarak Ekstraksiyonu ve Menton, İsomenton ve Pulegon Miktarı Üzerine Ekstraksiyon Koşullarının Optimizasyonu

Çizelge 5. Pulegon için önerilen kuadratik modelin Anova sonuçları

\begin{tabular}{|c|c|c|c|c|c|}
\hline Source & $\begin{array}{c}\text { Sum of } \\
\text { Squares }\end{array}$ & df & $\begin{array}{c}\text { Mean } \\
\text { Square }\end{array}$ & f Değeri & $\begin{array}{c}\text { p-değeri } \\
\text { Prob }>\text { F }\end{array}$ \\
\hline Model & 1054,60 & 9 & 117,18 & 5,95 & 0,0319 \\
\hline $\mathrm{X}_{1}$ & 0,050 & 1 & 0,05 & $2,520 \mathrm{E}-03$ & 0,9619 \\
\hline $\mathrm{X}_{2}$ & 410,55 & 1 & 410,55 & 20,86 & 0,0060 \\
\hline $\mathrm{X}_{3}$ & 28,35 & 1 & 28,35 & 1,44 & 0,2839 \\
\hline $\mathrm{X}_{1} \mathrm{X}_{2}$ & 13,88 & 1 & 13,88 & 0,7 & 0,4394 \\
\hline $\mathrm{X}_{1} \mathrm{X}_{3}$ & 17,14 & 1 & 17,14 & 0,87 & 0,3936 \\
\hline $\mathrm{X}_{2} \mathrm{X}_{3}$ & 73,96 & 1 & 73,96 & 3,76 & 0,1103 \\
\hline $\mathrm{X}_{1}{ }^{2}$ & 64,47 & 1 & 64,47 & 3,28 & 0,1301 \\
\hline $\mathrm{X}_{2}{ }^{2}$ & 377,31 & 1 & 377,31 & 19,17 & 0,0072 \\
\hline $\mathrm{X}_{3}^{2}$ & 130,33 & 1 & 130,33 & 6,62 & 0,0498 \\
\hline Residual & 98,42 & 5 & 19,68 & & \\
\hline Lack of Fit $\mathrm{R}^{2} 0,91$ & 90,78 & 3 & 30,26 & 7,91 & 0,1143 \\
\hline
\end{tabular}

Şekil 5'de sabit ekstraksiyon süresi için $(25 \mathrm{dk})$ basınç ve sıcaklık değişimlerinin menton derişimi üzerine etkisini göstermektedir. Şekil 5'de görüldüğü gibi basınç artışıla yaklaşık 245 atm'ye kadar menton derişimi artmakta ve sonra bir miktar azalmaktadır. Sıcaklığın artışı ile menton derişimi fazla değişmemektedir.

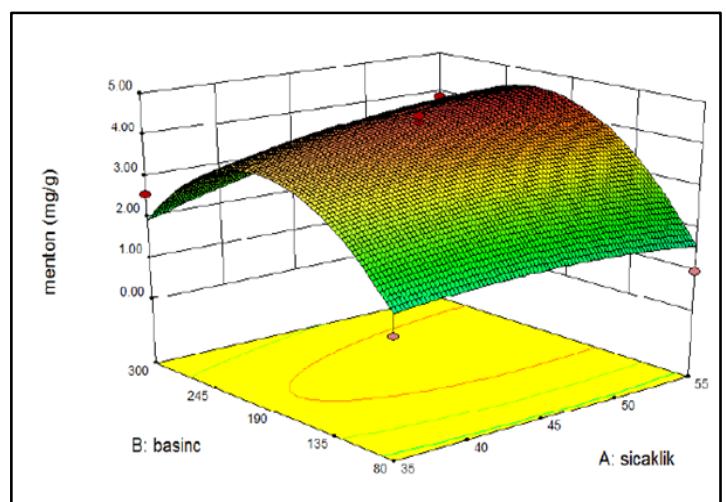

Şekil 5. Basınç ve sıcaklık değişimlerinin menton derişimi üzerine etkisi

Şekil 6'da sabit basınç için (190 atm), süper kritik ekstraksiyon süresi ve sicaklık değişimlerinin menton derişimi üzerine etkisini göstermektedir. Ekstraksiyon süresinin yaklaşık ilk 25 dakika artmasıyla menton derişiminin arttığı ve daha sonraki dakikalarda ciddi bir şekilde azaldığ görülmektedir.

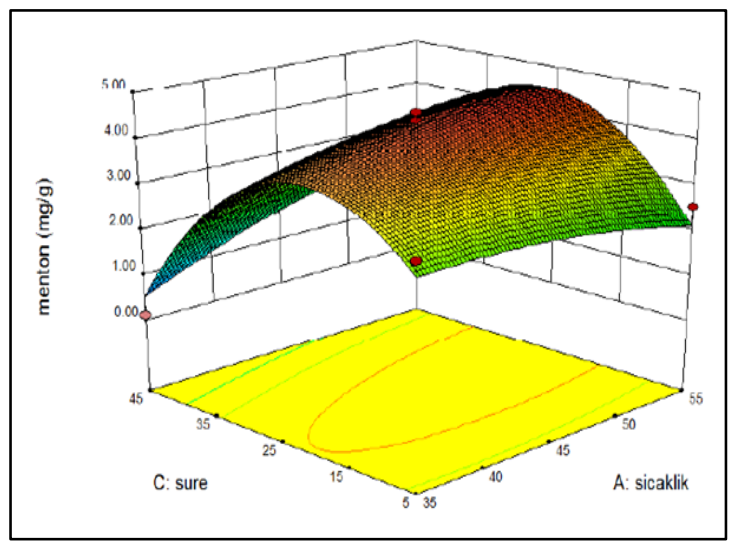

Şekil 6. Süre ve sıcaklık değişimerinin menton derişimi üzerine etkisi

Şekil 7'de sabit sıcaklık (45 $\left.{ }^{\circ} \mathrm{C}\right)$, süper kritik ekstraksiyon süresi ve basınç değişimlerinin menton derişimi üzerine etkisini göstermektedir. Ekstraksiyon süresinin artmasıyla önce menton derişiminin arttığ 1 (yaklaşık ilk 25 dakika) ve daha sonra menton derişiminin azaldığı görülmektedir. Şekil 7'de görüldüğü gibi basınç artışıyla yaklaşık 245 atm ye kadar menton derişimi artmakta ve sonra bir miktar azalmaktadır.

Maksimum menton derişimi için yanıt yüzey yöntemi sonucunda en uygun sicaklik $52,93{ }^{\circ} \mathrm{C}$, basınç 208,48 atm ve süre 26,58 dakika olarak belirlenmiştir. 


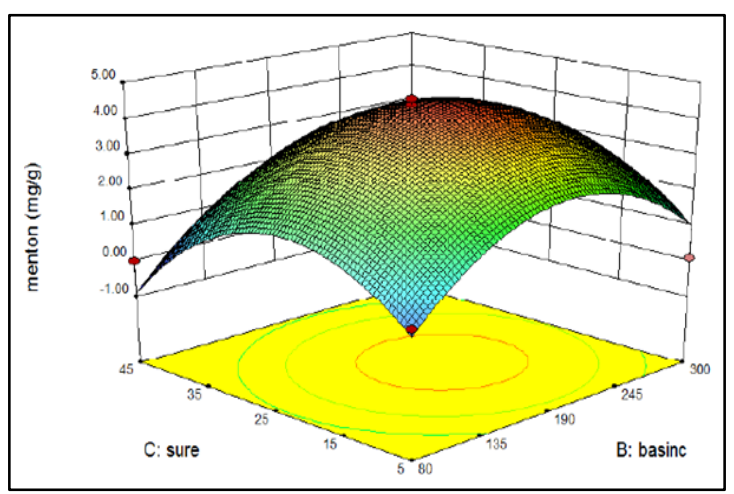

Şekil 7. Süre ve basınç değişiminin menton derişimi üzerine etkisi

Şekil 8'de sabit süper kritik $\mathrm{CO}_{2}$ ekstraksiyon süresi için $(25 \mathrm{dk})$ basınç ve sıcaklık değişimlerinin isomenton derişimi üzerine etkisini göstermektedir. Şekil 8'den görüldüğü gibi basınç artışıyla isomenton derişimi artmakta yaklaşık 300 atm ye yakın basınçlarda bir miktar azalmaktadır. Sicaklığın artışı ile isomenton derişimi fazla değişmemektedir.

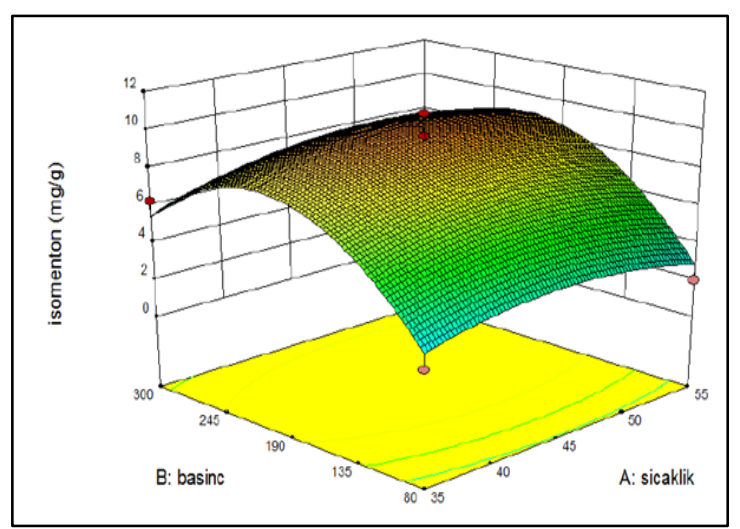

Şekil 8. Basınç ve sıcaklık değişimlerinin isomenton derişimi üzerine etkisi

Şekil 9'da sabit basınç için (190 atm), süper kritik ekstraksiyon süresi ve sicaklık değişimlerinin isomenton derişimi üzerine etkisini göstermektedir. Ekstraksiyon süresinin yaklaşık ilk 30 dakika artmasıyla isomenton derişiminin arttığı ve daha sonra ki dakikalarda ciddi bir şekilde azaldığı görülmektedir. Sicaklıktaki değişim isomenton derişimi değişimini fazla etkilemediği tespit edilmiştir.

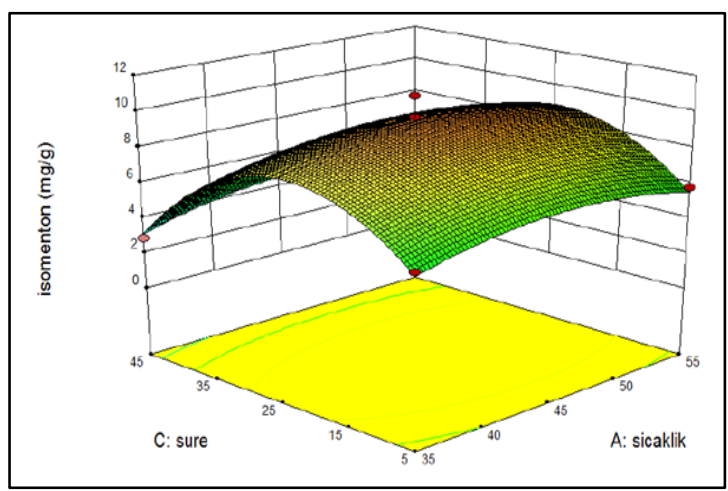

Şekil 9. Süre ve sıcaklık değişimlerinin isomenton derişimi üzerine etkisi

Şekil $10^{\prime}$ da sabit sıcaklık $\left(45{ }^{\circ} \mathrm{C}\right)$, süper kritik ekstraksiyon süresi ve basınç değişimlerinin isomenton derişimi üzerine etkisini göstermektedir. Ekstraksiyon süresinin artmasıyla önce isomenton derişiminin arttığ 25 dakika) ve daha sonra isomenton derişiminin azaldığı görülmektedir. Şekil 11'de görüldüğü gibi basınç artışıla yaklaşık 245 atm ye kadar isomenton derişimi artmakta ve sonra bir miktar azalmaktadır.

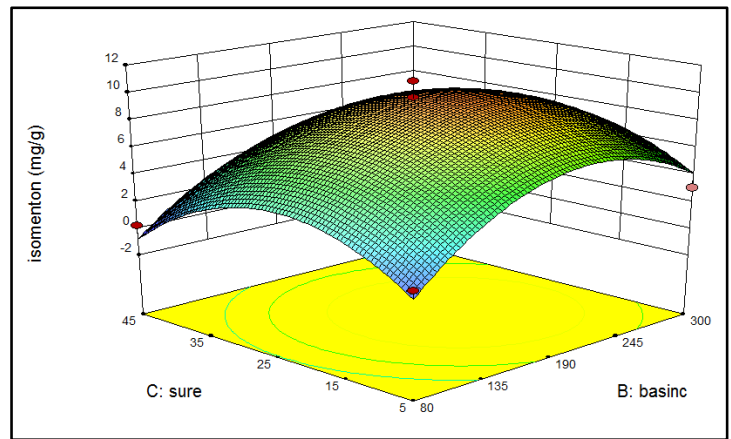

Şekil 10. Süre ve basınç değişimlerinin isomenton derişimi üzerine etkisi

Maksimum isomenton derişimi için yanıt yüzey yöntemi sonucunda en uygun sicaklık $46,70{ }^{\circ} \mathrm{C}$, basınç $212,49 \mathrm{~atm}$ ve süre 22,76 dakika olarak belirlenmiş̧tir.

Şekil 11'de sabit süper kritik $\mathrm{CO}_{2}$ ekstraksiyon süresi için $(25 \mathrm{dk})$ basınç ve sıcaklık değişimlerinin pulegon derişimi üzerine etkisini göstermektedir. Şekil 11 'de görüldüğü gibi basınç 
Micromeria Fruticosa L. Druce'un Süper Kritik Karbondioksit Kullanılarak Ekstraksiyonu ve Menton, İsomenton ve Pulegon Miktarı Üzerine Ekstraksiyon Koşullarının Optimizasyonu

artışıyla pulegon derişimi artmakta ve sonra bir miktar azalmaktadır. Sıcaklığın artışı ile pulegon derişimi fazla değişmemektedir.

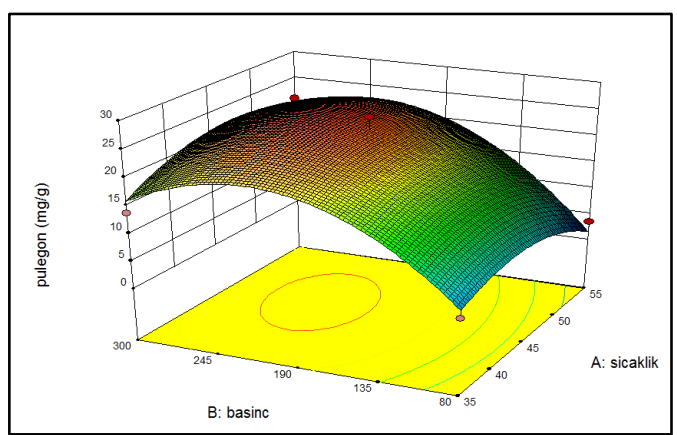

Şekil 11. Basınç ve sıcaklık değişimlerinin pulegon derişimi üzerine etkisi

Şekil 12'de sabit basınç için (190 atm), süper kritik ekstraksiyon süresi ve sicaklık değişimlerinin pulegon derişimi üzerine etkisini göstermektedir. Ekstraksiyon süresinin artmasiyla pulegon derişiminin arttığı ve 35 dakika'dan sonra kısmen azaldığı görülmektedir. Sıcaklıktaki değişimin diğer bileşenlerin aksine pulegon derişimini artırdığı tespit edilmiştir.

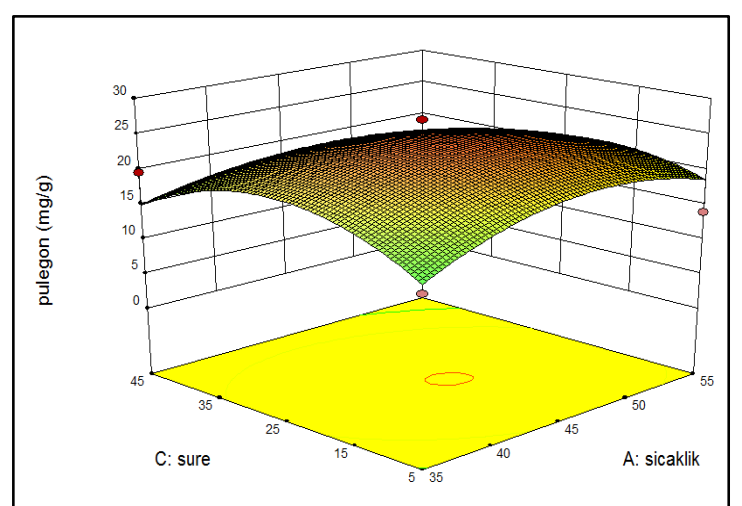

Şekil 12. Süre ve sıcaklık değișimlerinin pulegon derişimi üzerine etkisi

Şekil 13'de sabit sıcaklık $\left(45^{\circ} \mathrm{C}\right)$, süper kritik ekstraksiyon süresi ve basınç değişimlerinin pulegon derişimi üzerine etkisini göstermektedir. Ekstraksiyon süresinin artmasıyla diğer bileşenlerden farklı olarak pulegon derişiminin arttığı görülmektedir. Şekil 11'de görüldüğü gibi basınç artışıyla pulegon derişimi artmıştır.

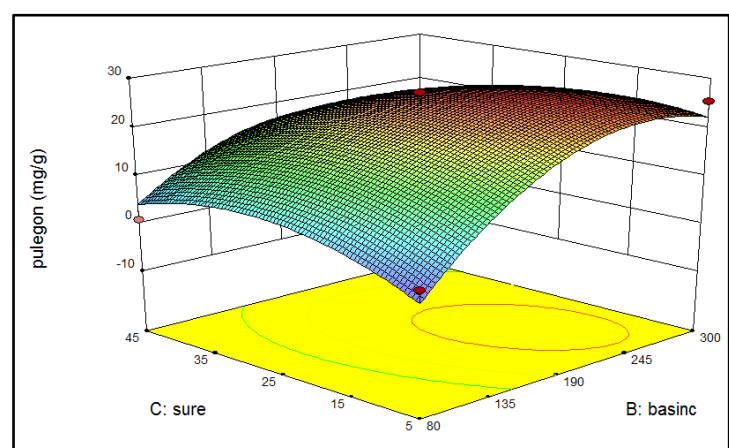

Şekil 13. Süre ve basınç değişimlerinin pulegon derişimi üzerine etkisi

Maksimum pulegon derişimi için yanıt yüzey yöntemi sonucunda en uygun sicaklık $46,77{ }^{\circ} \mathrm{C}$, basınç 238,92 atm ve süre 18,00 dakika olarak belirlenmiştir.

Süper kritik $\mathrm{CO}_{2}$ akışkanının basıncının artması yoğunluğunu da artırmıştır. Ancak, basınç belli bir noktaya kadar ekstrakte etme gücünü artırabilmiştir. Çok yüksek basınçlarda bu güç bir miktar azalmıştır. Çok yüksek basınçlarda süper kritik akışkan yoğunluğu daha da yükseleceğinden kütle transferi, difüzyon ve ekstrakte etme gücünün bir miktar olumsuz etkilediği saptanmıştır [14-16].

Sıcaklık değişiminin genel olarak bileşenlerin derişimleri üzerinde fazla etkili olamadığı tespit edilmiştir. Fakat ekstraksiyon süresi ile birlikte sıcaklığın da artması süper kritik akışkanın yoğunluğunu düşürdüğünden, kütle transferi, difüzyon ve ekstraksiyon gücünün olumsuz etkilendiği gözlenmiştir [14-16].

Micromeria fruticosa L. Druce'un süper kritik $\mathrm{CO}_{2}$ ekstraksiyonunda menton, isomenton ve pulegon maksimum derişimleri için tahminlenen en uygun sıcaklık 47,16 ${ }^{\circ} \mathrm{C}$, basınç 216,99 atm ve süre 22,45 dakika olarak bulunmuştur.

Kullanılan bitkiler veya tohumların ekstraksiyonu için kullanılan parametreler ve değerleri ile uygulanan deneysel yöntem farklılık gösterse de bu çalışmadan elde edilen bulguların literatürdeki benzer çalışmalarla uyumlu olduğu gözlenmiştir. Literatürde Hindistan orjinli kurutulmuş Syzygium 
aromaticum Linn'den eugenolun izole edilmesi süperkritik karbon dioksit kullanılarak ekstraktsiyonu gerçekleştirilmiş ve optimum sıcaklık $60{ }^{\circ} \mathrm{C}$, basınç 250 bar ve ekstraksiyon süresini 90 dakika olarak belirlemişlerdir [21]. Süper kritik karbon dioksit kullanılarak Echium vulgare tohumlarının ekstraksiyonu ile yapılan bir başka çalışmada, yağın ekstraksiyon verimi üzerine test koşulları arasında anlamlı değişimler elde edilmiştir. Optimum deneysel koşulları ise $62{ }^{\circ} \mathrm{C}$ ve 400 bar olarak bulunmuştur [22]. Ekstraksiyon sıcaklığı, basınç ve akış hızının optimum değerlerinin $36{ }^{\circ} \mathrm{C}, 42 \mathrm{MPa}$ ve $17 \mathrm{~L} / \mathrm{sa}$ olarak belirlendiği Schisandra Chinensis (Turcz.) Baill'in süper kritik karbon dioksit kullanarak ekstraksiyonunu inceleyen bir başka çalışmada, yağ verimi \%0,43 olarak hesaplanmıştır. Sonuçlar, verilerin ikinci derece polinomiyal modelinin yeterli bir şekilde uygun olduğunu göstermiştir [23]. Micromeria fruticosa L. Druce'un subkritik su ekstraksiyonu olmuştur. Micromeria fruticosa L. Druce'un sub kritik su ekstraksiyonu ile temel bileşenlerin miktarları, 1,06-0,04 (mg menton/g bitki); 3,79-0,35 (mg isomenton/g bitki) ve 5,55-0,65 (mg pulegon/g bitki) olarak belirlenmiştir. $\mathrm{Bu}$ verilere göre süper kritik $\mathrm{CO}_{2}$ ekstraksiyonunun daha etkin olduğu saptanmıştır. [24].

\section{SONUÇLAR}

Micromeria fruticosa L. Druce'un süper kritik $\mathrm{CO}_{2}$ ortamında ekstraksiyonu ile menton, isomenton ve pulegon temel bileşenleri için yüzey yanıt yöntemi kullanılarak optimizasyonunda, istatistiksel olarak anlamlı bir model oluşturulmuştur.

$\mathrm{Bu}$ çalışmada, optimum basınç ve ekstraksiyon süresinin ekstraksiyon gücüne katkısının daha fazla olduğu belirlenmiştir.

Temel bileşen miktarının verimliliği açısından süper kritik $\mathrm{CO}_{2}$ ekstraksiyonun optimizasyonu literatüre katkı sağlayacağı düşünülmektedir.

$\mathrm{Bu}$ çalışmadan elde edilecek sonuçların özellikle farmakolojik çalışmalarda kullanılması, temel bileşenlerin biyolojik aktiviteye etkilerinin incelenmesi açısından farklı bir yaklaşım sağlayacaktır.

\section{TEŞEKKÜR}

$\mathrm{Bu}$ çalışmada Çukurova Üniversitesi Bilimsel Araştırma Koordinasyonu Birimi tarafindan desteklenmiştir (Proje numarası: FEF2011BAP14).

\section{KAYNAKLAR}

1. Güllüce, M., Sökmen, M., Şahin, F., Sökmen, A., Adigüzel, A., Özer, H., 2004. Biological Activities of the Essential Oil and Methanolic Extract of Micromeria Fruticosa (L) Druce ssp Serpyllifolia (bieb) PH Davis Plants from the Eastern Anatolia Region of Turkey, J. Sci Food Agric 84(7), 735-741.

2. Telci, I, Ceylan, M., 2007. Essential Oil Composition of Micromeria Fruticosa Druce from Turkey, Chemistry of Natural Compounds, 43(5), 629-631.

3. Ietswaart, J.H., 1980. A Taxonomic Revision of the Genus Origanum (Labiatae), 4, Leiden.

4. Davis, P.H., 1985. Flora of Turkey and the East Aegan Island, 7, Edinburg.

5. Vera, R.R., Change-Ming, J., 1999. Chemical Composition of the Essential Oil of Marjoram (Origanummajorana L) form Reunion Island. Food Chemistry, 66, 143-145.

6. Guner, A., Ozhatay, N., Ekim, T., Baser, K.H.C., 2001. Flora of Turkey and the East Aegean Islands, University Press, Edinburg, Vol:11, (Suplement2)

7. Berger, G.R., Flavours and Fragrances. Springer, Germany.

8. Reidah, A.M.I., Roman, A.D., Nuri, A.M., Warad, I., Carretero, S.A., 2019. Untargeted Metabolite Profiling and Phytochemical Analysis of Micromeria fruticosa L. (Lamiaceae) leaves, Food Chemistry, 279, 12-143.

9. Gharbieh, A.E., Ahmed, G.N., 2016. Bioactive Content, Hepatoprotective and Antioxidant Activities of Whole Plant Extract of Micromeria Fruticosa (L) Druce ssp Serpyllifolia F Lamiaceae Aganist Carbon Tetrachloride-induced Hepatoxicity in Mice, 
Micromeria Fruticosa L. Druce'un Süper Kritik Karbondioksit Kullanılarak Ekstraksiyonu ve Menton, İsomenton ve Pulegon Miktarı Üzerine Ekstraksiyon Koşullarının Optimizasyonu

Tropical Journal of Pharmaceutical Research, 15, 2099-2106.

10. Salameh, N., Shraim, N., Jaradat, N., 2018. Chemical Composition and Enzymatic Screening of Micromeria fruticosa serpyllifolia Volatile Oils Collected from Three Different Regions of West Bank, Palestine, Hindawi Biomed Research International, 1-8.

11. Arslan, M., 2012. Effect of Intra-Row Spacing On Herbage Yield, Essential Oil Content and Composition of Micromeria Fruticosa, Farmacia, 60, 925-931.

12. Vetere,V., Santori, F.G., Moglioni, A., Iglesias, M.Y.G., Casella, L.M., Ferretti, A.O., 2002. Hydrogenation of (-)- Menthone, $(+)-$ Isomenthone, and $(+)-$ Pulegonewith Platinum/tin Catalysts, Catalysis Letters 84, 251-257.

13. Türk, M., 2010. Bazı Önemli Tıbbi Bitkilerin Kimyasal Kompozisyonu ve Antioksidan Kapasitelerinin Belirlenmesinde Sub ve Süperkritik Akışkanların Etkisi, Ç.Ü. Doktora Tezi, Fen Bilimleri Enstitüsü, Adana, Sayfa No: 1-3.

14. Chrastil, J., 1982. Solubility od Solids and Liquids in Supercritical Gases, Journal of Physical Chemistry, 86, 3016-3021.

15. Yamini, Y., Sedifidkon, F., Pourmortazavi, M. S., 2002. Comparison of Essential Oil Composition of Iranian Fennel (Foeniculum vulgare) Obtained by Supercritical Carbon Dioxide Extraction and Hydrodistillation Methods, Flavour and Fragrance Journal, 17, 345-348.

16. Reverchon, E., 1992. Fractional Seperation of SCF Extracts from Marjoram Leaves: Mass Transfer and Optimization, The Journal of Supercritical Fluids, 5, 256-261.

17. Box, G.E.P., Wilson, K.B., 1951. On the Experimental Attainment of Optimum Conditions (with discussion). Journal of the Royal Statistical Society Series B, 13(1), 1-45.

18. Chen, H., $1994 . \quad$ Response-surface Methodology for Optimizing Citric Acid Fermentation by Aspergillus Foetidus, Proses Biochem, 29, 399-405.

19. Joglekar, A.M., May, A.T., 1987. Product Excellence Through Design of Experiments, Cereal Foods World. 32(12), 857-860.
20. Türk, B., 2008. İmmobilize Lipaz Enzimi Kullanılarak Etil Bütirat Üretimi, A.Ü. Yüksek Lisans Tezi, Fen Bilimleri Enstitüsü, Ankara.

21. Montgomery, D.C., 1996. Design and Analysis of Experiments 4, John Wiley and Sons Ltd., USA.

22. Anderson, M.J., Whitcomb, P.J., 2005. RSM Simplified-optimizing Processes Using Response Surface Methods for Design of Experiments, Productivity Inc., New York.

21. Chatterjee, D., Bhattacharjee, P., 2013. Supercritical Carbon Dioxide Extraction of Eugenol from Clove Buds, Food Bioprocess Technol 6, 2587-2599.

22. Keleş, B.S., Yeşilçubuk Ş.N., Demirkoz, B.A., Karakaş, M., 2019. Response Surface Optimization and Modelling for Supercritical Carbon Dioxide Extraction of Echium vulgare Seed Oil, The Journal of Supercritical Fluids, 143, 365-369.

23. Meng, X.L.B., Xue, X.L.Y., 2010. Use of BoxBehnken Design for the Optimization of Supercritical Carbon Dioxide Extraction of Oil from Schisandra Chinensis (Turcz) Bail, $3^{\text {rd }}$ International Conference on Biomedical Engineering and Informatics (BMEI), United States, 670-674.

24. Türk, M., Ç.Ü. Bilimsel Araştırmaları Proje Birimi, FEF2011BAP14 Nolu Proje, Adana, 2014. 